\title{
СБЛИЖЕНИЕ ФОРМ ВЕЖЛИВОСТИ В СЛАВЯНСКИХ ЯЗЫКАХ НА МАТЕРИАЛАХ РУССКОГО, ЧЕШСКОГО, УКРАИНСКОГО ЯЗЫКОВ
}

\author{
Approximation of Political Forms in Slavic Languages on the Materials of Russian, \\ Czech, Ukrainian Languages
}

Keywords: Czech language, Russian language, Ukrainian language, politeness, treatment, greetings, culture

Contact: МГПУ; ulyanova.kris01@yandex.ru

Вежливость - это норма общественной жизни. Всюду, куда бы вы ни пришли: в магазин, на почту, в учреждение, в канцелярию школы - везде следует вежливо поздороваться, поблагодарить за обслуживание (информацию, услугу) и попрощаться, так заведено и в России, и в других странах. Чтобы осознать важность использования форм вежливости, необходимо на своем опыте познакомиться с международным характером вежливости. Выбрать для такого знакомства нужно такие языки, которые были бы с одной стороны иностранными, «чужими», с другой - понятными и близкими по происхождению. Такими являются славянские языки. Для наших материалов мы выбираем один более близкий русскому и один далекий в рамках славянской группы от русского славянский язык - украинский и чешский.

\section{Приветствия}

C приветствия начинается общение. Оно выполняет важную функцию в коммуникативном процессе. От него зависит первое впечатление о человеке, которое образуется спонтанно и зависит от искренности слов собеседника. Если человек позитивно настроен, это отражается в приветствии лексически и интонационно, и, если человек вовсе не жаждет разговаривать, отвечать собеседнику, это тоже заметно и понятно с первых слов.

В умении выбрать уместную форму приветствия сказывается общая и речевая культура. Выбор зависит от того, в каком окружении находится человек, 
от возраста собеседника или собеседников, от характера отношений между людьми, которые здороваются или прощаются, от того, где и когда это происходит и т. д.

Формул приветствия в русском языке сравнительно немного, но всегда можно подобрать нужное высказывание, исходя из конкретной ситуации, чтобы выразить уважение к личности, например: Добрый день! - самое распространенное приветствие. Выражение «добрый» - прилагательное, синонимами которого является славный, доброжелательный, благоприятный. Исходя из этого, мы понимаем, что слово «добрый» несет положительную коммуникативную интенцию. А целое выражение означает: 'пожелание хорошего дня, удачи в течение дня'. Обычно его используют как в книжном, так и в разговорном стиле речи. Приветствия Здравствуйте! и Добрый день! ограничиваются разговорным стилем литературного языка. В зависимости от времени дня для поздравления с коллегами или сотрудниками используют также поздравления Доброе утро! и Добрый вечер!

В чешском языке люди приветствуют друг друга подобно тому, как в русском языке, утром можно сказать Dobré jitro! или Dobré ráno!, чуть позже Dobrý den!, Dobrý večer!, также в любое время уместно Zdravím!, Čau! и Ahoj!. В сельской местности в Чехии принято вести себя подчеркнуто вежливо. При встречи здороваться и спрашивать у собеседника Как дела? (чеш. Jak se máš?), но это совершенно не значит, что нужно рассказывать от и до, как прошел день, делиться своими чувствами, настроением, не обязательно отвечать на вопрос детально. Риторичность этого вопроса в равной мере свойственно и русскому, и украинскому языку.

В украинском языке есть большое количество народных приветствий, например: Доброго ранку, Драстуйте, Дай Бог, Добрий день, Доброго вечора, Привіт, Дай Бог. Так же существуют и сакральные приветствия, такие как: Христос воскрес, Христос народжується, Христос рождается.

В итоге сказанного можно сделать следующий вывод. Смысловая значимость приветствия на трех языках одинаковая. Все выражения, которые являются вежливой формой приветствия, несут положительную коммуникативную интенцию.

Что касается звучания, то мы сразу обращаем внимание на мягкость и твердость звуков. Например, украинское и чешское «і» мягче, чем русское. Так же в чешском и украинском буква «е» произносится близко к русскому «э», но более мягко. 
Если сравнивать написание, то русский и украинский имеют больше сходств, чем различий. В Чехии для написания слов используют латинские буквы, а в России и Украине кириллические. Но в украинском алфавите, оформившемся в конце XIX столетия, в отличие от русского не используются буквы «Ёё», «Ђъ», «Ыы», «Ээ», но зато присутствуют «ГГ», «Єє», «Іі», «Ії», которых нет в русском.

Важнейшим выводом, однако, является следующий: смысловая значимость приветствия на трех языках одинаковая. Все выражения являются вежливой формой приветствия, несут добрый посыл.

\section{Обращение}

Существуют две формы обращения: на «ты» и на «вы». На «ты» обычно обращаются к родным и близким, к знакомым и друзьям, к детям, а на «вы» к незнакомым людям, к более старшему поколению.

Такие правила вежливости заведены как в Украине, так и в Чехии, так и в России. Человек может сам выбирать, к кому обращаться на «ты», а к кому на «вы». Но если человек придерживается правил этикета, значит он уважает окружающих, значит он вежлив по отношению к ним.

Что касается русского языка, т. е. русского речевого этикета, вежливости, то не трудно заметить, что в основном люди обращаются вопросительным предложением, не называя собеседника. Например: Простите, как пройти...?, Извините, можно вас на минутку?, Простите, можно у вас спросить? и т. д. Такие обращения можно услышать как в официальной форме, так и в обыденной, неофициальной. Они носят нейтрально-вежливый характер.

Если собеседник никуда не торопится, то его обращение будет звучать иначе: Не затруднит ли вас сказать мне..., Прошу прощения за беспокойство, вы мне не скажете.... Эти формы более вежливые и длинные.

Также, чтобы привлечь внимание прохожего, часто используют прямые обращения. Они основаны на таких чертах, как: пол, возраст, общественное положение. Например: молодой человек, юноша, так обращаются в основном пожилые люди по отношению к молодежи. Молодые люди в общении между собой используют либо косвенные формулы обращения: простите, либо неэтикетные формулы: парень, приятель.

Приставки, которые есть в иностранных языках, например, мистер, месье - в русском языке отсутствуют. Раньше они были в ходу, но в современном мире эти приставки устарели. 
До революции использовали такие обращения как: сударь, сударыня, затем их сменили на гражданин и товарищ. Обращения господин и госпожа использовались с фамилией: господин Семенов, названием должности: господин министр и т. д. Такого рода обращения не слишком популярны, они вызывают некое неудобство. Если нужно обратиться к незнакомцу, многие русские предпочтут использовать обычные выражения типа девушка, женщина, мужчина, молодой человек. Подойдет и безликое извините, пожалуйста для привлечения внимания. Обращение господа характерно для деловой сферы - юристов, предпринимателей, должностных лиц. Коллеги - характерное обращение для интеллигентской среды (научной, педагогической) или группы единомышленников.

Рассмотрим обращение в чешском языке. В Чехии часто можно услышать такие слова, как pani (госпожа) и рап (господин). Их принято добавлять к имени, фамилии или профессии, к определенным должностям. Например: pan ředitel господин директор, paní Anпа Кис̌еrová - госпожа Анна Кучерова, paní učitelka госпожа преподавательнииа.

В разговоре с человеком важна научная степень, от этого будет зависеть форма обращения к нему, если имеет, то название степени присоединяется к имени и фамилии. Например: paní doktorka Anna Kučerová - госпожа доктор Анна Кучерова. Помимо paní, pan в Чехии есть еще одна форма обращения slečna (мисс, девушка).

В чешском языке есть звательный падеж, особенный падеж, который почти ушел из русского литературного языка, сохраняясь только в архаичных формах: боже, отче. В русском просторечии (нелитературной форме существования языка) звательный падеж появился вновь в форме с нулевым окончанием для существительных первого (главным образом, женского) склонения: мам, nan, Kamb. В чешском языке звательный падеж используют при обращении к кому-то или когда нужно позвать человека. Некоторые слова немного меняются в написании. В звательном падеже у местоимения изменяется окончание, вследствие слово звучит чуть по-другому.

Этот падеж служит для выражения обращения. В социально-ролевой коммуникативной ситуации: в торговом центре, в аптеке, в ресторане или в любом другом общественном месте, если обращаются к женщине - paní, то следует использовать в разговоре paní!; если вы ведете беседу с девушкой - slečna, то говорите ей slečno!; а если с мужчиной - pan, то pane!. Также можно добавить имя, фамилию или звание после этих форм. Например: Dobrý večer, pane doktore! - 
Добрый вечер, господин доктор! Итак, например, у вас есть знакомый доктор pan doktor. Если мы обращаемся именно к нему, тогда мы говорим в звательной форме: pane doktore. И получается: Dobrý večer, pane doktore! - Добрый вечер, господин доктор!

Распространенные формы обращения в чешском языке: dámy a pánové! дамы и господа!, mladý тиži! - молодой человек!, drazi př́telé! - дорогие друзья! весьма созвучны с русским и украинским.

Еще одной особенностью чешского языка является то, что обращение к человеку зависит от рода (мужского или женского). Если в русском языке многие обращения имеют форму только мужского рода, например: магистр, доцент, профессор, то в чешском при обращении к девушке, слово преобразуется в женский род, ср.: magistr / magistra-магистр, обращение: pane magistře! (муж. p.), paní magistro! (жен. p.); docent / docentka - доцент, обращение: pane docente! (муж. p.), pani docentko! (жен. p.); professor / profesorka - nрофессор, обращение: pane profesore! (муж. p.), pani profesorko! (жен. р.).

В украинском языке также встречается ряд форм обращения. В восточной части, часто можно услышать прямое обращение: мужчина - чоловік, или молодой человек - легінь, или женщина - жінка, или девушка - дівчина, так обращаются к незнакомым, к прохожим, когда нужно узнать какую-любо информацию или спросить что-то. Когда человек ведет речь со знакомым, с другом или с родственником, он обращается по имени. Если собеседник старше, то принято обращаться по имени-отчеству. В деловом этикете прибавляют к имени-отчеству должность, например: министр, Владимир Николаевич. В официальном обращении к людям, говорят господа, если выделяют кого-то одного, то произносят гражданин, гражданка + фамилия. В западной части Украины обращение к мужчине - naн, к замужней женщина - naни, а к девушке панянко.

\section{Общий вывод}

Чешский, русский, украинский языки относятся к одной языковой группе славянской, данные языки имеют общие корни, система грамматических правил в них похожа, и некоторые слова созвучны.

Многие слова на чешском языке имеют общий корень с русскими и украинскими словами, только используются в неполногласной форме. В чешском языке много согласных и мало гласных. В отличие от русского и украинского чешский язык сохранил множество архаичных форм. Например, 
в нем есть звательный падеж, который в русском языке превратился в обращение, выделяемое запятой.

Нужно отметить, что все рассмотренные славянские языки располагают весьма разветвленными и обширными средствами вежливости, которые реализуются не только в лексике, но и в грамматике, в частности в звательном падеже, или в наличии специальных форм вежливого единственного в форме множественного числа. Это свидетельствует об особой ценности вежливости в культуре славянских народов, что в наибольшей мере проявляется в чешском языке, где не утрачен исторически существовавший у всех славян звательный падеж.

\section{Summary}

Czech, Russian, and Ukrainian belong to the same language group - Slavic, these languages have common roots, the system of grammatical rules in them are similar, and some words are consonant. Many words in Czech have a common root with Russian and Ukrainian words, but they are used in an incomplete form. In the Czech language many consonants and not enough vowels. In contrast to the Russian and Ukrainian Czech language has retained many archaic forms. For example, it has a Vocative case, which in Russian has become a comma-separated address. It should be noted that all the considered Slavic languages have very extensive and extensive means of politeness, which are implemented not only in vocabulary, but also in grammar, in particular in the Vocative case and in the presence of special forms of the polite singular in the plural form in the pronoun and verb. This indicates the special value of politeness in the culture of Slavic peoples, which is most evident in the Czech language, where the Vocative case that historically existed among all Slavs has not been lost.

\section{Литература}

Акишина, А. А., Формановская, Н. И. Русский речевой этикет. Москва: Русский язык, 1983.

Лихачев, С. В. О фамильярности в речи учителя. Русский язык и литература в школах Украиньл. 2003 (1), с. 12-14.

Лихачев, С. В. Сударь и братан, братишка и хозяин. Формы обращения к собеседнику. Журналистика и культура русской речи. 2003 (2), с. 18-20.

Формановская, Н. И. Речевой этикет и культура речи. Москва: Высшая школа, 1989. 


\section{Интернет-источники}

Режим доступа: https://pressa.tv/interesnoe/51705-otlichiya-russkogo-i-ukrainskogoyazykov-6-foto.html (2020-04-25).

Режим доступа: https://www.pragueacademy.ru/chekhiya/etiket (2020-04-25).

Режим доступа: https://yandex.ru/turbo?text=https\%3A\%2F\%2Fstud.wiki\%2 Flanguages\%2F3c0a65625b3bc68b4d53b88421216d37_0.html (2020-04-25). 